\title{
A participação do trabalhador na fábrica: contrastes entre as propostas do modelo japonês e as propostas autogestionárias
}

HENRIQUE NOUAES"

RENATO DAGNINO"*

\section{Resumo}

Este artigo é resultado de uma pesquisa sobre a participação do trabalhador na empresa. Ele contrasta as propostas de participação ensejadas pelo modelo japonês com as de viés autogestionário. A revisão bibliográfica apresentada, cobre um espectro que vai das estratégias gerencialistas para cooptar a força de trabalho até a defesa de uma sociedade governada pelos produtores associados. Nossa conclusão é que as estratégias gerenciais - e aqui se insere o modelo japonês atacam o que poderiam ser considerados sintomas (e não, as causas) da alienação. Seu objetivo é que os trabalhadores decidam sobre tudo, menos sobre o essencial. Já as propostas autogestionárias propõem que o trabalhador participe da gestão dos problemas essenciais da empresa, da concepção de um novo tipo de processo de trabalho e da construção de uma sociedade produtora de valores de uso, de acordo com as possibilidades históricas. Existem entre elas diferenças que não se referem apenas ao grau de participação, mas à natureza desta participação.

Palavras-chave: Participação dos trabalhadores. Autogestão. Pseudo-participação. Modelo Japonês. Capitalismo.

\footnotetext{
* Doutorando no DPCT - Unicamp.

** Professor Titular do DPCT - Unicamp.
} 


\section{Introdução}

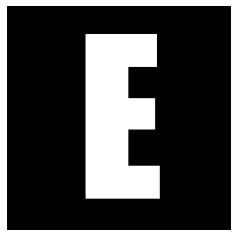

Antes de prosseguir, é importante destacar uma preocupação presente em nossos estudos: a facilidade com que a pedagogia toyotista se apropria sempre do ponto de vista do capital, de concepções elaboradas pela pedagogia socialista e, com isso, estabelece uma ambigüidade nos discursos e nas práticas pedagógicas. Essa apropriação tem levado muitos a imaginar que, a partir das novas demandas do capital no regime de acumulação flexível, as políticas e as propostas pedagógicas passaram a contemplar os interesses dos que vivem do trabalho, do ponto de vista da democratização. Assim é que categorias clássicas da pedagogia (só possíveis de objetivação plena em outro modo de produção) passaram a fazer parte do novo discurso pedagógico: formação do homem em todas as suas dimensões de integralidade com vistas à politecnia, à superação da fragmentação do trabalho em geral e em decorrência do trabalho pedagógico, ao resgate da cisão entre teoria e prática, à transdisciplinaridade, e assim por diante.

Torna-se necessário desemaranhar este cipoal e estabelecer os limites da pedagogia toyotista, para que se possa avançar na construção teórico-prática, nos espaços da contradição, de uma pedagogia de fato comprometida com a emancipação humana (KUENZER, 2003).

adeptos da autogestão.

Um olhar superficial nos deixaria a impressão de que os empresários estão promovendo políticas de participação do trabalhador na empresa que os levariam a cavar a sua própria cova. Ou, nas palavras de Frigotto 
(1995), como se eles estivessem fora da relação social de produção capitalista, o que leva a perguntar: "os homens de negócio mudaram suas concepções e seus interesses? Ou estamos diante de transformações que mudam efetivamente dentro da relação capitalista, sem, contudo, alterar a natureza desta relação?" (FRIGOTTO, 1995, p. 55).

Para Tragtenberg, "a linguagem tecnocrática emprega o termo 'inovação' em lugar de 'mudança'. Sucedem-se revoluções organizacionais que nada mudam, revoluções filosóficas que são revoluções filológicas" (TRAGTENBERG, 2005, p. 54).

Nesta linha de raciocínio, o autor afirma que

a exploração do trabalho no capitalismo desenvolvido, especialmente nos EUA, na sua prática, ainda está sob o signo do taylorismo, embora a retórica dominante do discurso administrativo patronal seja "sistêmica", ou "relações humanas", ou de "desenvolvimento organizacional" (TRAGTENBERG, 2005, p. 121)

No que se refere à relação inter-empresas, muitos estudos procuram evidenciar as mudanças proporcionadas pela reestruturação produtiva, principalmente no que se refere aos processos de terceirização e até mesmo, de quarteirização (LEITE, 2003; KUENZER, 2003; LIMA, 2001)'. Tendo em vista a relação Estado-Sociedade, Emir Sader aponta que estamos diante do Estado mínimo para os trabalhadores e máximo para o capital. A partir da década de 1970, mas principalmente nas décadas posteriores, as grandes corporações transnacionais vão ganhando maior poder de determinação dos rumos do capitalismo, em contraste com a fase anterior (1945-73) onde o Estado-Nacional dos países capitalistas desenvolvidos, em particular sob a égide da social-democracia européia, conseguia exercer uma regulação entre capital e trabalho. O que presenciamos a partir

1 Para a sistematização e as controvérsias deste debate, ver Leite (2003), Invernizzi (2004) e Salerno (2004). 
de 1973 é a crescente apropriação dos fundos públicos pelo capital (FRIGOTTO, 1995) e a forte intervenção do Estado para garantir as condições de acumulação de capital financeiro, tendo como referência o quadro em que este artigo analisa as políticas de participação do trabalhador na empresa. Acreditamos, como sugere Tragtenberg, que nenhuma forma de organização do trabalho supera radicalmente a divisão do trabalho anterior, mas se sobrepõe à mesma (BRUNO, 2006), promovendo mudanças marginais, sem que se altere a essência da relação social capitalista, que é baseada na exploração da força de trabalho pelo capital.

Disso decorre nossa inquietação: em que medida as propostas participacionistas atualmente em voga têm um caráter de fato emancipatório? O modelo japonês supera radicalmente - no sentido de ir à raiz dos problemas - o taylorismo-fordismo, ou se trata de uma mudança que não altera a natureza da relação de classes no capitalismo, como sugerem Frigotto e Tragtenberg?

Nesta introdução, já cabe adiantar que, para autores como Hirata (1990), os Círculos de Controle de Qualidade (CCQs) não representam, de forma alguma, "uma produção controlada pelos trabalhadores, mas sim uma organização [informal], em pequenos grupos para discutir e resolver problemas diagnosticados no local de trabalho". Para ela, os CCQs diferem das propostas autogestionárias "pela própria natureza e não só em grau (HIRATA, 1990, p. 136).

Para Tragtenberg (2005), as propostas ensejadas pelo capital a partir dos anos 1960, que vão desde políticas de estímulo à participação do trabalhador nas decisões de assuntos marginais até à participação nos lucros e resultados, são, na verdade, uma "pseudo-participação", pois quem, de fato, participa e controla a produção nesta nova fase de acumulação é o capital financeiro.

No nosso entender, a apropriação do discurso socialista pelo capital e sua re-significação é, no mínimo alarmante, como sugere Kuenzer (2003) 
na epígrafe deste artigo ${ }^{2}$. Com o objetivo de trazer para o debate os argumentos daqueles que estão desemaranhando este cipoal, o artigo contrasta e delimita as propostas participacionistas vislumbradas pelo capital nesta nova fase histórica, com as propostas de participação voltadas para a construção de uma sociedade governada pelos produtores associados.

Aqui uma dificuldade deve ser evidenciada. Acreditamos que o processo de trabalho no capitalismo é moldado pela luta capital-trabalho. Neste sentido, os trabalhadores conformam as iniciativas dos empresários, da mesma forma que os capitalistas moldam as iniciativas da classe operária, o que torna difícil explicitar os limites de cada proposta de participação. Isso nos leva a crer que nunca haverá, numa empresa, um processo totalmente puro que possa ser entendido como uma iniciativa dos capitalistas ou dos trabalhadores ${ }^{3}$. O produto da luta de classes no chão-de-fábrica, por estar sempre sendo construído e reconstruído, será o resultado desta luta contínua, o que dificulta a análise dos avanços e retrocessos para a emancipação dos trabalhadores.

Para Frigotto, os avanços e retrocessos "teimam em existir na mesma totalidade e num mesmo processo histórico e sua definição se dá pela correlação de força dos diferentes grupos e classes sociais" (FRIGOTTO, 1995, p. 144). Porém, por mais que haja luta no processo de trabalho, as classes não têm o mesmo poder de intervenção no processo de trabalho (NOBLE, 1979; NOVAES, 2005, DAGNINO, 2006), e o poder da ideologia atua no sentido de evitar essa luta (MÉSZÁROS, 2004).

Dois pontos adicionais precisam ser enfatizados nesta introdução. Sobre a palavra autogestão, Valeska Guimarães et al. (2004) já constataram sua polissemia. Alguns empregam a palavra para caracterizar as Fábri-

2 Quando nos referimos ao discurso socialista, estamos nos espelhando em Marx e nos críticos da organização do trabalho capitalista. Aliás, não podemos nos esquecer que Lênin admirava Taylor e aplicou os seus princípios, métodos e técnicas no processo de trabalho na antiga URSS. Sobre isso, ver Bryan (1992) e Novaes (2007).

3 Sobre este debate, ver Novaes, Assis e Dagnino (2004), Leite (1994) e Noble (1979). 
cas Recuperadas (FRs), as cooperativas de trabalhadores, etc. Neste caso, essas autoras preferem usar o termo empreendimentos com características autogestionárias ${ }^{4}$. Usaremos a palavra autogestão para designar processos mais amplos da vida, como sugere Tiriba (2001) numa palestra na UFMG:

Particularmente, prefiro não adjetivar um empreendimento de "autogestionário". Talvez fosse um pouco mais humilde de nossa parte dizer que nestes processos produtivos [de cooperativas populares, fábricas recuperadas] os trabalhadores se inspiram nos princípios da autogestão para poder repensar a organização do trabalho. Penso que chamar, de antemão, esses processos de autogestionários é reduzir o significado da autogestão a um processo que é vivido apenas entre as quatro paredes de um estabelecimento. Como vimos em outras mesas deste seminário, a autogestão diz respeito aos processos mais amplos da vida (TIRIBA, 2001).

Concordamos então com Guimarães, Korosue e Corrêa (2004, p. 5) que a "autogestão não pode ser resumida apenas aos limites das empresas". Contudo, quando nos remetemos à autogestão nas empresas, adotaremos, assim como estas autoras, o sentido estrito do termo para poder abordar a "autogestão e seu conteúdo numa dimensão microeconômica, ou seja, no interior das organizações" (GUIMARÃES et al., 2004, p. 5). Neste caso, iremos estranhar a palavra através da fonte itálica.

Mészáros (2002), Burawoy (1990a), Bettelheim (1979), J. Faria (1987) e Guillerm e Bourdet (1976) dentre outros, cada qual à sua maneira, também não acreditam que a autogestão deva ser resumida ao seu sentido estrito (NOVAES, 2008). Eles ressaltam que a participação do trabalhador deve ocorrer não somente dentro dos muros das fábricas, mas que deve ser substancialmente de outra natureza ${ }^{5}$.

4 Sobre as Fábricas Recuperadas e Cooperativas de Trabalhadores, ver Novaes (2005b), Cruz (2006) e Faria (2005).

5 Talvez tenha sido por essa dificuldade que preferimos importar a palavra Fábricas Recuperadas da Argentina e Uruguai, ao invés de usar a palavra empreendimentos de autogestão ou empresas de autogestão que vem sendo disseminada no Brasil. Para ver a forma como a 
Guillerm e Bourdet, por exemplo, afirmam que

Os leitores de presente obra [Autogestão: uma visão radical] se convencerão sem esforço de que, para nós, a autogestão deve ser compreendida em sentido generalizado e que não se pode realizar senão por uma revolução radical, que transforme completamente a sociedade em todos os planos, dialeticamente ligados, da economia, da política e da vida social (GUILLERM; BOURDET, 1976, p. 18).

O segundo ponto é que este artigo faz parte da primeira etapa de uma pesquisa em andamento que tem por objetivo observar que tipo de concepção de participação e qual arsenal teórico os assessores (engenheiros, etc) de FRs deveriam ter em mente ao realizarem seu trabalho. Nosso interesse sobre o tema decorreu de uma entrevista que fizemos com um consultor de uma FR. Inquietou-nos o fato de que este consultor possuía em sua mesa (na qual decidia sobre os aspectos de sua consultoria à $F R$ ) um livro sobre as técnicas japonesas e disse que iria utilizar na FR "todo aquele arsenal". Imediatamente nos veio a pergunta: as ferramentas utilizadas pelo modelo japonês são neutras? Elas servem para os propósitos da autogestão nas fábricas de trabalhadores? Antes de tentar responder esta questão (que, é claro, não foi por nós formulada ao consultor), propusemo-nos a dar um passo atrás e escrever este artigo. Depois de concluída esta etapa da pesquisa, iremos abordar os possíveis motivos que levam esses consultores a tentar adotar as técnicas japonesas em FRs.

$\mathrm{O}$ artigo foi estruturado da seguinte forma. Para analisar as diferentes propostas de participação, que vão desde as estratégias gerencialistas para cooptar a força de trabalho, até às propostas de participação para

palavra 'autogestão' foi apropriada e re-significada no Brasil, ver Faria (2005). Dentre outras coisas, alguns autores brasileiros, principalmente os participantes do movimento da Economia Solidária, vislumbram a autogestão dentro dos muros das empresas e a competição no mercado, numa sociedade socialista, o que seria uma contradição para autores como Mészáros (2002) e Guillerm e Bourdet (1976), críticos do socialismo de mercado. 
construir a autogestão, faremos uma breve análise de política da participação dos trabalhadores na empresa. O texto tem um caráter de sistematização da bibliografia sobre as diferentes concepções de participação dos trabalhadores na fábrica. Encerramos o artigo com algumas considerações finais sobre esta parte da pesquisa.

\section{Uma análise da participação do trabalhador na fábrica}

De acordo com Storch (1985), nunca se sabe se as propostas de participação serão boas ou ruins para os trabalhadores, o que nos leva a crer que devemos destrinchar e analisar os seus propósitos. É esta a intenção desta seção.

Pateman (1992), refletindo sobre as implicações do tipo de participação na empresa e na sociedade, enfatiza que muitos autores não incluem como participação, situações como as seguintes: a) quando um indivíduo apenas toma parte numa atividade do grupo; b) quando apenas é informado sobre uma decisão que o afeta, antes que seja executada; c) quando está presente em uma reunião, mas não exerce influência alguma.

Para Pateman (1992), influência e poder não têm o mesmo significado, porquanto "estar em posição de influenciar uma decisão não é o mesmo que estar em posição (ter o poder para) determinar o resultado ou tomar essa decisão" (PATEMAN, 1992, p. 96).

Segundo Pateman (1992), existem duas formas de participação, a parcial e a plena. A primeira ocorre nas situações em que os trabalhadores podem influenciar as decisões, mas a prerrogativa da decisão final permanece com a direção da empresa. É dela o poder e o controle sobre a decisão final. A participação plena acontece quando cada membro isolado de um corpo deliberativo tem igual poder de determinar o resultado final da decisão: "Neste tipo de situação, não existem dois lados com poderes desiguais de decisão, mas um grupo de indivíduos com poderes iguais para decidir" (PATEMAN, 1992, p. 98). 
Importa, também, distinguir os níveis decisórios em que a participação se efetiva. Alguns autores, como Connerley (1974) e Pateman (1992), preferem distinguir apenas dois níveis: a) níveis mais baixos, nos quais ocorrem as decisões rotineiras que afetam as condições de trabalho, o nível de produção, a atribuição e a execução de tarefas; b) alto nível, associado às decisões mais importantes da empresa (estratégicas), que possuem conseqüências a longo prazo, como a definição das suas políticas e diretrizes gerais.

Outros autores discriminam os três níveis organizacionais em que a participação pode ocorrer: operacional, tático e estratégico $(\mathrm{STORCH}$, 1985). A participação pode limitar-se a determinado(s) níveis ou atingir todos os níveis (GUIMARÃES, 1995).

Quanto à base formal em que se assenta a participação, duas formas distintas podem coexistir: as legalmente estabelecidas e as voluntárias, categorizadas por alguns como, respectivamente, ou formal, e de facto ou real. A participação 'de jure' é estabelecida a partir dos sistemas legais e formais, incluindo as normas operativas e regras escritas, no âmbito da empresa e fora dela. A participação de facto ou real, ao contrário da anterior, não está prescrita formalmente e depende da capacidade efetiva dos trabalhadores em se organizarem para atuar sobre o processo decisório (GUIMARÃES, 1995, p. 84).

\section{As estratégias do capital: aumento da produtividade e apropriação do saber tácito}

De acordo com Burawoy (1990b), no século XX, o capital encontrou diversas formas de controle da força de trabalho. Andrew Friedman (1977) contestou a visão unilinear de Braverman (1987) sobre a degradação do trabalho e ressaltou a importância da resistência operária na configuração de duas estratégias gerenciais: controle direto e autonomia responsável. Se o contro- 
le direto leva necessariamente à desqualificação, a autonomia responsável atrela os operários aos interesses do capital, permitindo-lhes um controle limitado sobre as tarefas, e uma unidade também limitada entre concepção e execução. No período inicial do capitalismo, a autonomia responsável era um legado do passado e tomou a forma de controle de ofício, enquanto no capitalismo monopolista, passa a ser uma estratégia gerencial consciente, de prevenção contra a resistência operária (BURAWOY, 1990b).

Segundo Faria (2004) e Guimarães (1995), é possível traçar uma diferença entre as estratégias do capital (gerenciais) e as estratégias dos trabalhadores. Nas estratégias do capital, a questão central é a manipulação do trabalhador para que a empresa atinja a eficácia máxima dos resultados organizacionais

As estratégias da gerência atacam - como não poderia deixar de ser - os sintomas da alienação e não, as suas causas . Nelas podem ser enquadradas as propostas de criação de CCQs, Kanban e as estratégias enriquecedoras de cargos, sendo a participação, não um direito do trabalhador, mas uma arma do capital para comprar a alma do trabalhador (SILVA, 2001) ou um meio de regulação de conflitos, uma vez que já não é mais possível administrá-lo através da coação física, como sugere Motta (1982)

Para Tragtenberg (2005), trazendo este debate para os anos 196070, "o fato é que no período de capitalismo monopolista de Estado, tanto na empresa quanto no Estado, a burguesia reforça o caráter autoritário do Estado, de um lado; de outro, intensifica a pressão ideológica mediante "panacéias" administrativas que se constituem em pseudogestão e pseudoparticipação" (TRAGTENBERG, 2005, p. 111).

Em perspectiva histórica, Tragtenberg narra os motivos que levaram à mudança da estratégia empresarial:

Na década de 1950, com o aumento dos técnicos, engenheiros e trabalhadores do terciário, e maior desgaste nervoso no trabalho, a aplicação de relações humanas coloca- 
se imediatamente. É o período em que surgem obras sobre relações industriais, sugerindo a diplomacia em lugar do autoritarismo nas relações patrão-operário. Na França, a "humanização do trabalho", na Itália, sob influência católica, com o lema "humanização na empresa"; na Alemanha, pelas técnicas de co-gestão, as relações humanas têm uma vida transfigurada (TRAGTENBERG, 2005, p.32) ${ }^{6}$.

É interessante destacar que a onda participacionista surgida na França, foi precedida de uma série de decretos que iam contra os assalariados. Tais decretos levaram à alta dos preços, em detrimento dos assalariados e aposentados, anulando cláusulas que estabeleciam correspondência entre salários e preços. Aumentaram as taxas de juros, tarifas de transportes e correios. Verificou-se, em suma, uma ação ofensiva contra o nível de vida dos trabalhadores (TRAGTENBERG, 2005).

Tragtenberg observa também que as estratégias de geração de consentimento na fábrica via participação e a associação entre trabalhadores e capitalistas, não são muito novas. Pela sua importância, este longo trecho do autor merece destaque:

A idéia de que patrões e assalariados devam ser considerados como "associados" mediante uma "participação dos trabalhadores" nos lucros não é nova. Em 1838, o Conde de Laborde já sugeria isso, no reinado de Luis Felipe. Em 1844, a Sociedade de Economia Política discutia esse tema: "Que se deve pensar da participação nos lucros como meio de evitar as greves?" Em 1891, o Marquês de La Tour du Pin elaborou projetos que consideravam a empresa como associação entre capital e trabalho [...] Na escala social, a "associação capital e trabalho" mascara a exploração do trabalho pelo capital e tem por fim encerrar os assalariados no horizonte da empresa, pondo-os em concorrência uns com os outros, para maior proveito da classe capitalista em seu

6 "Como os trabalhadores da automobilística vêem a teoria das relações humanas? Como uma forma de tirar mais leite, formando vacas alegres" (TRAGTENBERG, 2005, p. 36). 
conjunto, levando o assalariado a criar um valor suplementar para além do valor relativamente mínimo que corresponde ao salário (TRAGTENBERG, 2005, p. 107).

Podemos dizer que Tragtenberg divide sua análise da participação na fábrica, entre a óptica dos trabalhadores e a óptica empresarial. Na óptica dos trabalhadores, tema da nossa próxima seção, o participacionismo teve como motor os "Delegados de Pessoal", criados por ocasião da Frente Popular de 1936 na Espanha. Eles se constituíram num instrumento da classe trabalhadora para controlar a produção e decidir democraticamente o papel das empresas na sociedade (TRAGTENBERG, 2005).

$\mathrm{Na}$ óptica dos empresários não se aceita dividir a autoridade na empresa. Eles aceitam o participacionismo nas trocas de informações, admitem a consulta, a delegação de responsabilidades, sem colocar em xeque a decisão. É por isso que, para os trabalhadores, o participacionismo aparece como a "nova ratoeira do capital" (TRAGTENBERG, 2005, p. 109).

A participação dos trabalhadores na discussão da produtividade, dentre outros aspectos, é uma "técnica utilizada para enganar o público e dar impressão, à mão-de-obra, de que ela possui papel importante nas decisões, o que é uma farsa" (TRAGTENBERG, 2005, p. 35).

Ricardo Antunes (2007) considera que a implantação dos métodos participativos é parte do intento do capital em criar o "envolvimento" dos trabalhadores, na verdade, adesão e sujeição dos mesmos aos planos das empresas.

É lógico que, comparada à direção patronal de direito divino, a participação ou a co-gestão aparece como algo renovador, sugere Tragtenberg. Contudo, "a legalização dos conselhos de empresa ou sua seção sindical, o direito de reunir-se regularmente na mesma não são suficientes para garantir uma espécie de "dualidade de poder" na empresa" (TRAGTENBERG, 2005, p. 109-110). 
É por isso que Tragtenberg (2005) afirma que a impossibilidade de uma gestão real dos meios de produção pela mão-de-obra significa, na prática, via instrumentos como a pseudo-participação, um reforço do modo de produção capitalista. Em outras palavras, como as empresas, no capitalismo, não são geridas pelos próprios produtores, a participação e o diálogo tomam a forma de extração do conhecimento operário com vistas a arrancar maior produtividade (TRAGTENBERG, 2005).

Outra estratégia utilizada pelos empresários é a participação nos lucros. Para Tragtenberg, o assalariado é levado a trabalhar com mais vigor, intensificando sua exploração, sem um aumento correspondente na sua remuneração real, na esperança de obter uma fração do lucro. (TRAGTENBERG, 2005, p. 107) ${ }^{7}$.

No livro A Fábrica como Agência Educativa, Silva (2005) caminha na mesma direção que Tragtenberg. Ele afirma que a ideologia da empresa flexível avança no momento em que o processo de (des)construção da sociedade de bem-estar-social coloca-se como uma inevitablilidade histórica e concorre, de maneira acelerada, para a redefinição da forma de exploração do trabalho. Emerge, no final do século XX, um novo fenômeno conhecido como flexploração e precarização do trabalho, isto é, gestão racional da força de trabalho, por meio da insegurança, do medo de perder o emprego (SILVA, 2005).

Para Tragtenberg (2005) e Silva (2005), dentre outros, a fábrica não é somente uma instituição voltada para a extração do trabalho excedente,

\footnotetext{
7 Um estudo recente (DIEESE, 2006) sobre a Participação nos Lucros ou Resultados (PLRs) é elucidativo. Comentando o estudo, afirma a Folha de São Paulo: "O que mais chamou a atenção dos especialistas [do Dieese] foi o fato de a conquista da PLR estar associada à realização de greves. No setor industrial, por exemplo, a busca de divisão de lucros motivou $33,7 \%$ das greves que ocorreram em 2005". Em entrevista à Folha de São Paulo (2006), Daniel Huertas, técnico do Dieese responsável pela pesquisa, afirma que "esse percentual ultrapassou até a motivação de fazer paralisações por reajustes salariais, que foi de 31,4\% em 2005". Esses dados dispensam comentários. Eles ilustram bem o poder de atração que as PLRs exercem sobre a classe trabalhadora.
} 
mas é também aparelho ideológico. Neste sentido, o Conselho de Fábrica atua como agente de tranquilização e pacificação social, tornando-se um dos instrumentos de manipulação ideológica.

O toyotismo - ou ohnoísmo - cria, na realidade, um trabalhador pluriparcelar engajado e flexível. A fábrica, mediante uma pedagogia participativa, apropria-se do saber-tácito e da subjetividade humana levando a intensificação do ritmo do trabalho ao paroxismo nas empresas de produção discreta (SILVA, 2005) .

Para Tragtenberg, o capital percebeu que, se os grupos informais não podem ser destruídos, "manda a boa técnica das relações humanas que sejam "reconvertidos"“ (TRAGTENBERG, 2005, p.35).

Para Bernardo, "em vez de romper com os ciclos básicos do taylorismo, o toyotismo prolongou-os no que diz respeito à intensificação do trabalho e aplicou-os de maneira inovadora aos problemas específicos do trabalho intelectual" (BERNARDO, 2004, p. 86).

A contribuição de dois educadores, Acácia Kuenzer e Gaudêncio Frigotto, também nos parece válida para desemaranhar este cipoal que entrelaça as propostas dos trabalhadores com as do capital. De acordo com Kuenzer (2003), o regime de acumulação flexível, ao aprofundar as diferenças de classe, reforça a dualidade estrutural como expressão da polarização das competências (KUENZER, 2003, p. 77).

Dentre as demandas do novo processo produtivo, Kuenzer acredita que o foco está em superar o desperdício (controle de qualidade feito pelo trabalhador). No entanto, essa política de controle de qualidade feita pelo próprio trabalhador não tem como objetivo reconstruir a unidade rompida entre trabalho intelectual e manual, mas evitar a perda e assim ampliar as possibilidades de valorização do capital (KUENZER, 2003). Mais precisa-

8 Cumpre observar que, apesar deste novo modelo nascer nas empresas de produção discreta, ele se espraia enquanto ideologia de outros setores e até mesmo no Estado. 
mente, a "finalidade das novas formas de organização, ao aumentar as possibilidades de reprodução ampliada do capital, não supera, mas aprofunda a divisão entre capital e trabalho" (KUENZER, 2003, p. 81).

Ao analisar as demandas por educação dos trabalhadores e dirigentes, Kuenzer (2003) verifica uma clara definição de fronteiras entre trabalho intelectual e manual. Apesar de verificar que, desde os anos 1990, está havendo uma educação de trabalhadores de novo tipo, considera que se acirra nesta nova fase, ao contrário do que diz o novo discurso do capital, a cisão entre o trabalho intelectual, que compete a um número cada vez menor de trabalhadores, com formação flexível, resultante da prolongada e contínua capacitação, e o trabalho instrumental, cada vez mais esvaziado de conteúdo (KUENZER, 2003).

Frigotto (1995) nos traz a análise das relações entre sociedade, processo de trabalho e educação, e indiretamente, da participação do trabaIhador na fábrica.

Segundo Frigotto (1995), o caráter subordinado das práticas educativas aos interesses do capital toma formas e conteúdos historicamente diferenciados no capitalismo nascente, no capitalismo monopolista e no capitalismo transnacional ou na economia globalizada.

No livro Produtividade da escola improdutiva, Frigotto (1984) procura explicitar as condições históricas do capitalismo monopolista, que demandaram, produziram e configuraram a teoria do capital humano.

Já em Educação e a crise do capitalismo real, Frigotto (1995) nos mostra que as novas demandas de educação, contidas em documentos dos novos "senhores do mundo baseadas nas categorias sociedade do conhecimento, qualidade total, educação para a competitividade, e formação abstrata e polivalente, expressam os limites da teoria do capital humano e as redefinem sob novas bases" (FRIGOTTO, 1995, p. 18). 
Para ele, a mudança de aparência da Teoria do Capital Humano $(\mathrm{TCH})$ ocorre nos anos $1980^{9}$. Ela surge nessa época com novos conceitos e categorias que aparentemente não apenas superam aquelas perspectivas, como lhes são opostas. Trata-se, na verdade, de uma metamorfose de conceitos, sem, todavia, alterarem-se fundamentalmente as relações sociais que mascaram (FRIGOTTO, 1995).

A partir deste momento histórico, surgem novas categorias-ponte: flexibilidade, participação, trabalho em equipe, competência, competitividade e qualidade total. E é aqui que Frigotto se pergunta se esta

mudança de enfoque seria a explicação real de que a "nova (des)ordem" mundial, sob a égide das sociedade do conhecimento, estaria efetivamente delineando novas relações não-classistas, pós-industriais e, portanto, de processos educativos e de formação humana desalienados e não subordinados aos desígnios do capital? Os homens de negócio mudaram suas concepções e seus interesses? Ou estamos diante de transformações que mudam efetivamente dentro da relação capitalista, sem, contudo, alterar a natureza desta relação? (FRIGOTTO, 1995, p. 55-56).

O primeiro desafio para qualquer pesquisador é o de qualificar a base histórico-social das quais emergem essas novas exigências educativas e de formação humana - rejuvenescimento da $\mathrm{TCH}$ - e de decifrar por que motivo as teses de uma formação geral e abstrata que prepara sujeitos polivalentes, flexíveis e participativos aparecem no mesmo momento em que surgem as perspectivas neoconservadoras de ajuste no campo econômicosocial e no campo social mediante as leis de mercado (FRICOTTO, 1995).

Para ele, este movimento de mudança das categorias e a necessidade de conservar a natureza excludente das relações sociais, especificam os dilemas e contradições que o capital e os homens de negócio historica-

9 A ideia chave da TCH é a de que a um acréscimo marginal de instrução, treinamento e educação corresponde um acréscimo marginal de capacidade de produção (FRIGOTTO, 1995). 
mente encontram para adequar a educação aos seus interesses. Ao mesmo tempo, explicita um espaço de contradição, dentro do qual é possível desenvolver uma alternativa de sociedade e de educação democráticas que concorram para a emancipação humana (FRIGOTTO, 1995, p. 19).

Para Frigotto, a mudança que o capital engendrou no campo da educação é a necessidade de combinar a já existente educação básica com a capacidade de abstração (FRIGOTTO, 1995). Na atual fase, o capital depende de trabalhadores com capacidade de abstração e de trabalho em equipe.

Em sua essência, a TCH é a mesma das propostas vigentes nas fases anteriores e está circunscrita à órbita do capital, pois submete o conjunto dos processos educativos escolares ao imediatismo da formação técnicoprofissional restrita (FRIGOTTO, 1995). Na TCH rejuvenescida, a valorização da educação básica geral para formar trabalhadores com capacidade de abstração, polivalentes, flexíveis e criativos fica subordinada à lógica do mercado, do capital e, portanto, da diferenciação, segmentação e exclusão (FRIGOTTO, 1995, p. 145).

Desta forma, está na pauta do capital a criação de uma espécie de trabalhador super-homem: flexível, participativo, cooperativo, versátil, líder, que tenha princípios de moral, habilidade de discernir, equilíbrio físico-emocional. Além disso, ele deve ter uma boa base de conhecimentos (a cultura traz sensibilidade para gerir); é preciso conhecer expressões da cultura, da História, artes, grandes filmes (FRIGOTTO, 1995). No entanto, esta demanda real de mais conhecimento, mais cultura geral confronta-se com os limites imediatos da produção e da lógica do lucro (FRIGOTTO, 1995, p. 158).

\section{As estratégias dos trabalhadores: a concepção de participação dos adeptos da autogestão}

Para nós, cabe diferenciar - tal como sugerem Tragtenberg (2005), Guimarães (1995), Storch $(1985,1987)$ e Faria (2004) - as estratégias 
participacionistas promovidas pelo capital daquelas que a classe trabaIhadora tem utilizado historicamente para organizar a produção, sendo a autogestão das fábricas uma delas.

Sobre a distinção entre técnicas empregadas pela gestão participativa japonesa e formas participativas de autogestão ou de controle operário, onde os próprios trabalhadores administram a produção, convém lembrar a contribuição de Helena Hirata. Ela é enfática ao afirmar, analisando as formas de gestão participativa (como os CCQs), que as propostas “diferem pela própria natureza e não só em grau. Não se trata, de forma alguma, de uma produção controlada pelos trabalhadores, mas sim de uma organização [informal] em pequenos grupos para discutir e resolver problemas diagnosticados no local de trabalho" (HIRATA, 1990, p. 136) ${ }^{10}$.

Guillerm e Bourdet (1976) concordariam com Hirata, pois para eles, participar não significa necessariamente autogerir. Podemos depreender que quando esses autores se referem a autogestão eles têm em mente um novo tipo de participação, sem falar na necessidade de generalização do sistema de cooperativas na sociedade. Este novo tipo de participação não tem nada a ver com propostas participacionistas onde os trabalhadores decidem sobre tudo, menos o essencial.

Como vimos, para Faria (1987), a busca da participação do trabalhador, o enriquecimento de tarefas, o CCQ, Kanban, Kaizen, são estratégias utilizadas pelo capital para atacar os sintomas e não as causas da alienação do trabalho. Já a autogestão não nasce desta visão de participação, mas sim,

10 Para saber mais sobre o modelo japonês, ver Salerno (1993), Invernizzi (2004, Silva (2005), Antunes (2007) e Venco (2007), dentre outros. Antunes (2007) ressalta a heterogeneidade tecnológica no Brasil e a permanência do fordismo em diversos setores. Venco analisou o trabalho dos chamados teleoperadores, em geral mulheres que realizam a média de 140 ligações em uma jornada de seis horas, com pausa de 15 minutos, e precisam cumprir metas excessivas de produtividade em tempo preestabelecido. Segundo a socióloga, o setor de telemarketing e call center apresenta características do taylorismo, que consiste na racionalização do trabalho e minimização do excesso de rotinas (Jornal de Unicamp, 2007). 
das lutas históricas da classe trabalhadora nos séculos XIX e XX para levar a cabo a democracia na produção e, quem sabe, a construção de uma sociedade voltada para a satisfação das necessidades humanas ${ }^{11}$. Neste sentido, alienação significa perda do controle do processo de trabalho, do produto do trabalho, de si e da civilização humana (MÉSZÁROS, 2002).

Guimarães resolve este problema revisando a bibliografia sobre democracia industrial. Ela utiliza a expressão 'democratização industrial' "no sentido de caracterizar um processo contínuo (de avanço e retrocesso) que possibilita aos trabalhadores, enquanto "grupo dirigido"" ampliar a participação na tomada de decisões em todos os níveis (GUIMARÃES, 1995, p. 88) ${ }^{12}$.

Para Guimarães, a participação industrial deve ser entendida como um fim em si mesmo e não como um instrumento ou um meio de que se utiliza a direção das empresas para aumentar a eficiência e a eficácia organizacional (GUIMARÃES, 1995).

Se as estratégias gerencialistas procuram reduzir a participação do trabalhador à estreita necessidade de aumentar a produtividade da empresa e, com isso, permitir a reprodução do capital, as vertentes que advogam a autogestão adicionam a necessidade de participação fora do âmbito da empresa e propõem a participação dos trabalhadores no controle da sociedade ${ }^{13}$.

11 Guimarães, Korosue e Corrêa (2004) consideram que a autogestão ressurge como produto da sociedade capitalista e como produção de uma sociedade diferenciada, constituindo um processo dialético de transformações capitalistas de produção e das relações de trabalho. Isso, apesar de constatarem que os sujeitos do processo que fazem ressurgir a autogestão nas empresas, via de regra, não possuem a consciência de que a experiência autogestionária possa significar a transformação das relações de trabalho diferenciando-se da gestão tradicional capitalista, a heterogestão.

12 Verifica-se que Guimarães (1995) acredita acertadamente que a democracia é um processo e não um estado.

13 É evidente que o capital tem uma visão do que deveria ser a participação do trabalhador na sociedade (fora da empresa). No entanto, os limites deste artigo nos impossibilitam o aprofundamento da questão. Sobre este debate e sua relação com a democracia formal, elitista, substantiva, socialista, operária, minimalista, maximalista, etc, ver Wood (2003), Mészáros (2002), O’Donnell (1999) e Chomsky (1997). 
Greenberg (1975) considera Marx um dos pioneiros desta visão, uma vez que para ele, a condição do trabalhador de participante das decisões na empresa não seria suficiente, cabendo uma indispensável participação nos mecanismos de controle da sociedade (STORCH, 1987; GUIMARÃES, 1995).

De uma forma muito parecida, para Tragtenberg, a participação autêntica é aquela "onde a maioria da população, através de órgãos livremente eleitos e articulados entre si, tem condições de dirigir o processo de trabalho e participar da decisão a respeito das finalidades da produção e outros aspectos da vida social que tenham significado" (TRAGTENBERG, 1987, p. 30).

Motta também fala em participação autêntica, em contraposição às "modalidades de manipulação camufladas sob esse rótulo" (MOTTA, 2004, p.370). Para ele,

\begin{abstract}
a eventual construção de uma sociedade autogestionária passa inquestionavelmente pela questão da educação politécnica e polivalente, pela aprendizagem não-autoritária. Por aprendizagem não-autoritária entendo aquela que impede a internalização dos mecanismos de submissão e conformidade (MOTTA, 2004, p. 372).
\end{abstract}

Uma das visões mais radicais dentre as que defendem a autogestão das fábricas e da sociedade é a de István Mészáros. Ele tem em vista a construção, de acordo com as possibilidades históricas, de uma sociedade "para além do capital" (MÉSZÁROS, 2002). Mészáros nos dá algumas pistas sobre o que seria uma proposta de participação do trabalhador na fábrica e na sociedade, nos seus livros Para além do capital e A educação para além do capital. Na obra Para além do capital, ele propõe uma mudança global que tem por objetivo não só o fim do capitalismo, como sugerem outros, mas o definhamento progressivo do "sociometabolismo do capital" (MÉSZÁROS, 2002). Sua teoria vai em busca das exigências qualitativamente mais elevadas da nova forma histórica, o socialismo póscapital, no qual o ser humano possa desenvolver sua rica individualidade. 
Para construir esta nova sociedade, Mészáros parece concordar com os autores citados acima sobre a necessidade de outro tipo de participação não, só na empresa como, também uma indispensável participação nos mecanismos de controle da sociedade que estão alienados aos trabalhadores ${ }^{14}$.

\section{Considerações finais}

Há indícios que nos levam a pensar que estamos num período de regressão histórica. Presenciamos no período pós-1973, uma crise civilizatória, uma crise ecológica sem precedentes, a crise do socialismo real, o esgotamento do mais longo período de acumulação continuada do capital, a crise do Estado de Bem-Estar, o aumento da distância entre os países ricos e pobres e entre pobres e ricos dentro de cada país.

O capital deu diversas respostas à crise de acumulação dos anos 1970. No entanto, no nosso entender, não estamos presenciando uma busca efetiva de superação da crise e sim, uma tentativa de recomposição dos mecanismos de reprodução do capital pela exacerbação da exclusão social e de uma crescente apropriação dos fundos públicos pelas empresas privadas (FRIGOTTO, 1995). Para os defensores do capital, estamos numa sociedade pós-industrial, sem classes, não mais fundada na extração do trabalho excedente. Para os excluídos e para os que não se enquadram nessa categoria, para onde estaremos indo?

O objetivo deste artigo era desemaranhar o cipoal que hoje enreda as propostas de autogestão como o participacionismo proposto pelo capital. Se, para os defensores da autogestão a participação do trabalhador na fábrica tem em vista a construção de uma sociedade produtora de

14 Os adeptos da autogestão também destacam a necessidade de um novo processo de trabalho. Sobre este debate, ver Guillerm e Bourdet (1976), Invernizzi (2004), Novaes (2005b) e Novaes e Dagnino (2005). 
valores de uso governada pelos produtores associados, as propostas ensejadas pelo capital nesta sua nova fase buscam maximizar a extração de mais-valia através de uma nova onde de sistematização e expropriação do conhecimento tácito do trabalhador.

De acordo com Tragtenberg, a experiência histórica demonstra que o participacionismo proposto pelo capital não tem diminuído o poder da direção das empresas. Tampouco tem alterado o comando ditado pelo capital financeiro nesta nova fase do capitalismo (TRAGTENBERG, 2005).

O que escrevemos não é suficiente para desemaranhar este cipoal. Mas serve para dar os primeiros passos no desvelamento do novo discurso do capital sobre a participação dos trabalhadores na fábrica e seu contraste com a pedagogia engajada na emancipação humana. Serve também para colocar em relevo a diferença não só de grau, como nos dão a entender muitos pesquisadores, mas também de natureza entre o novo discurso do capital e as estratégias de emancipação que a classe trabalhadora está construindo.

\title{
Employee Participation in the company: contrasts between the Japanese model and the self-management proposals
}

\begin{abstract}
This article is the result of a research on the employees' participation in the company. It contrasts the proposals of participation suggested by the Japanese model with those of self-management. The literature review presented here covers a spectrum ranging from managerial strategies used to co-opt the labor force up to the defense of a society governed by the associated producers. The conclusion is that the managerial strategies - the Japanese model - attack the symptoms (and not the causes) of the alienation. It proposes the employees' participation on everything, except that which is essential. The self-management proposals, on the other hand, suggest the participation of the employee in the management of the
\end{abstract}


key problems of the company, in the establishment of a new type of work process as well as the creation of a society that produces use values, according to the historical possibilities. There are differences between them that are not restricted to the degree of participation, but also to the nature of that participation.

Keywords: Employee participation. Self-management. Pseudo-participation. Japanese model. Capitalism.

\section{Referências}

ANTUNES, R. A era da informatização e a época da informalização - riqueza e miséria do trabalho no Brasil. In: ANTUNES, R. (Org.) Riqueza e Miséria do Trabalho no Brasil. São Paulo: Boitempo Editorial, 2007, p. 15-25.

BERNARDO, J. Democracia totalitária: teoria e prática da empresa soberana. São Paulo: Cortez, 2004.

BETTELHEIM, C. A luta de classes na União Soviética. Rio de Janeiro: Paz e Terra, 1979.

BRAVERMAN, H. Trabalho e capital monopolista. Rio de Janeiro: Ed. Guanabara, 1987.

BRUNO, L. Palestra proferida em homenagem ao Maurício Tragtenberg. Campinas, Faculdade de Educação, Unicamp, maio de 2006.

BURAWOY, M. The politics of production. 3a. edição. Londres, Nova lorque: Verso, 1990a.

BURAWOY, M. A transformação dos regimes fabris no capitalismo avançado. Revista Brasileira de Ciências Sociais, São Paulo, v. 1, n. 13, ano 5, junho de 1990b. CARVALHO, R. Q., SCHMITZ, H. O Fordismo está Vivo no Brasil. Novos Estudos CEBRAP. São Paulo, n. 27, jul. 1990, p. 148-156.

CHOMSKY, N. Consentimento sem consentimento: a teoria e a prática da democracia. Estudos Avançados, São Paulo, USP, v. 11, n. 29, 1997, p. 259-276.

CONNERLEY, E. F. Participative management and a industrial Democracy: toward a participative theory of organization. Dissertation presented to the Faculty of the Graduate School: University of South Califórnia, 1974.

CRUZ, A. A diferença da igualdade. A dinâmica econômica da economia solidária em quatro cidades do mercosul. Tese de Doutorado. Campinas, Instituto de Economia, Unicamp, 2006.

DAGNINO, R. Um debate sobre a tecnociência: neutralidade da ciência e deter- 
minismo tecnológico. Campinas, no prelo, 2006.

DAGNINO, R.; NOVAES, H. T. As forças produtivas e a transição ao socialismo: contrastando as concepções de Paul Singer e István Mészáros. Revista Organizações \& Democracia, Unesp, Marília, v. 7, 2007, p. 60-80.

DIEESE. Participação dos trabalhadores nos lucros ou resultados das empresas 2005. Dieese, Estudos e Pesquisas, ano 3, número 22, agosto de 2006. Pode ser obtido em www.dieese.org.br

FARIA, José Henrique de. Comissões de Fábrica: poder e trabalho nas unidades produtivas. Curitiba: Criar Edições, 1987.

FARIA, José Henrique de. Economia Política do Poder. v. 2. Curitiba: Juruá, 2004.

FARIA, Maurício S. de. Autogestão, Cooperativa, Economia Solidária: avatares do trabalho e do capital. Tese de doutorado. Florianópolis, UFSC, Sociologia Política, 2005.

FRIEDMAN, A. Industry and Labour: Class struggle at work and monopoly capitalism. London: Macmillan, 1977.

FRIGOTTO, G. A produtividade da escola improdutiva. São Paulo: Cortez, 1984.

FRIGOTTO, G. Educação e a crise do capitalismo real. São Paulo: Cortez, 1995.

Folha de São Paulo. Indústria paga $73 \%$ dos acordos de ganhos sobre o lucro. Dinheiro, B7, 3/08/2006.

GUILLERM, A.; BOURDET, Y. Autogestão: uma visão radical. Rio de Janeiro: Zahar, 1976.

GUIMARÃES, V. N. Novas Tecnologias de Produção de Base Microeletrônica e Democracia Industrial: estudo comparativo de casos na indústria mecânica de Santa Catarina. 1995. Tese (Doutorado). Universidade Federal de Santa Catarina, Florianópolis, 1995.

GUIMARÃES, V. N. et al. Autogestão como estratégia de sobrevivência das organizações e dos trabalhadores: estudos multisetoriais no estado de Santa Catarina. Relatório de Pesquisa CNPq. Florianópolis, UFSC, 2004.

GREENBERG, E. The consequences of work participation: a clarification of the theoretical literature. Social Science Quarterly, n. 56, p. 191-209, set, 1975.

HARVEY, D. A condição pós-moderna. São Paulo: Edições Loyola, 1993.

HIRATA, H. Transferência de tecnologia de gestão:o caso dos sistemas participativos. In: SOARES, R.M. Automação e Competitividade. Brasília: IPEA, 1990, p. 135-148.

INVERNIZZI, N. Flexibles y disciplinados - los trabajadores brasileños frente a la reestructuración productiva. México: Editora da Universidad Autonoma de Zacatecas, 2004.

KUENZER, A. Z. Exclusão Includente e inclusão excludente: a nova forma de dualidade estrutural que objetiva as novas relações entre educação e trabalho. 
In: LOMBARDI, J. et al. (Orgs). Trabalho, Educação e Capitalismo. Campinas: Editora Autores Associados, 2003, p. 77-96.

LEITE, M. P. O futuro do trabalho: novas tecnologias e subjetividade operária. São Paulo: Scritta-Fapesp, 1994.

LEITE, M. P. Trabalho e Sociedade em transformação. São Paulo: Perseu Abramo, 2003. LEITE, M. P. Novas formas de gestão da mão-de-obra e sistemas participativos: uma tendência à democratização das relações de trabalho? Educação e Sociedade, Campinas, Papirus, n. 45, ago, 1993, p. 190-210.

LIMA, J. C. Interiorização industrial e fábricas cooperativas In: GUIMARÃES, N. A. e MARTIN, S. (orgs). Competitividade e Desenvolvimento: atores e instituições locais. São Paulo: Senac, 2001.

MÉSZÁROS, I. Para além do capital. Campinas: Editora da Unicamp, 2002.

MÉSZÁROS, I. A educação para além do capital. São Paulo: Boitempo editorial, 2005. MÉSZÁROS, I. O poder da ideologia. São Paulo: Boitempo editorial, 2004.

MOTTA, F. P. Participação e co-gestão. Novas formas de administração. São Paulo, Brasiliense, 1982.

MOTTA, F. P. Administração e Participação: reflexões para a educação. Educação e Pesquisa, São Paulo, v. 29, p. 369-373, jul./dez. 2003.

NOBLE, D. Social Choice in Machine Design. In: ZIMBALIST, A. (Org.). Case Studies on the labor process. Nova lorque: Monthly Review Press, 1979.

NOVAES, H.T. Para além da apropriação dos meios de produção? O processo de Adequação Sócio-Técnica em Fábricas Recuperadas. (Dissertação de Mestrado). Instituto de Geociências, Unicamp, Campinas, 2005b. Pode ser obtida em:

http://libdigi.unicamp.br/document/?code $=$ vtls000375370

NOVAES, H. T. O Fetiche da Tecnologia - a experiência das Fábricas Recuperadas. São Paulo: Expressão Popular, 2007.

NOVAES, H. T. Qual autogestão? Revista da Sociedade Brasileira de Economia Política. São Paulo, n. 22, maio de 2008.

NOVAES, H.; ASSIS, U.; DAGNINO, R. Mapeando mudanças em empresas recuperadas sob a óptica do conceito de Adequação Sócio-Técnica. In: 2o Encontro Internacional de Economia Solidária, junho de 2004, São Paulo, Resumos. (Artigo completo pode ser obtido em http://www.itcp.unicamp.br).

PATEMAN, C. Participação e teoria democrática. São Paulo: Paz e Terra, 1992.

SALERNO, M. S. Modelo Japonês, Trabalho Brasileiro. In: HIRATA, H. Sobre o "Modelo Japonês". São Paulo: Edusp, 1993. 
O’DONNELL, G. Teoria Democrática e Política Comparada. Dados, v. 42, n. 4, Rio de Janeiro, 1999.

RACHID, A. Tendências de organização da produção: questões suscitadas pelo Consórcio Modular. In: ENEGEP (Encontro Nacional de Engenharia de Produção), Gramado, 1997.

SALERNO, M. S. Flexibilidade, organização e trabalho operatório - Elementos para uma análise da produção na indústria. Tese de doutorado, USP, São Paulo, 1991.

SCHUMPETER, J. Capitalism, Socialism, and Democracy. New York: Harper, 1975.

SILVA, F. L. G. Uma breve reflexão sobre as harmonias administrativas: de F.W. Taylor a T. Ohno. In: ACCIOLY E SILVA, D.; MARRACH, S.A. (Org.) Maurício Tragtenberg - uma vida para as ciências humanas. São Paulo: Editora Unesp, 2001.

SILVA, F. L. G. A Fábrica como Agência Educativa. Araraquara: Editora Cultura Acadêmica-Unesp, 2005.

STORCH, S. Discussão da Participação dos Trabalhadores na Empresa. In: FLEURY, M.T.; FISCHER, R.M (Org.) Processo e Relações de Trabalho no Brasil. São Paulo: Ed. Atlas, 1985.

STORCH, S. Uma perspectiva estrutural sobre cooperativas industriais. In.: VENOSA, R. (Org.) Participação e participações: ensaios sobre autogestão. São Paulo: Babel Cultural, 1987, p. 61-91.

TIRIBA, L. Trabalho, educação e autogestão: desafios frente à crise do emprego. Obtido em www.uff.br/trabalhonecessario/Lia\%20TN3.htm. Belo Horizonte: UFMG, 2001. Acessado em junho de 2005.

TRAGTENBERG, M. Uma prática de participação: as coletivizações na Espanha (1936/1939). In: VENOSA, R. (Org.). Participação e participações: ensaios sobre autogestão. São Paulo: Babel Cultural, 1987.

TRAGTENBERG, M. Administração, poder e ideologia. São Paulo: Editora da Unesp, 2005. 3a ed.

VENCO, S. Telemarketing nos bancos - O emprego que desemprega. Campinas: Ed. da Unicamp, 2007.

VENCO, S. Tese expõe insalubridade no telemarketing. Jornal da Unicamp, março de 2007.

WOOD, E. M. Democracia contra capitalismo - a renovação do materialismo histórico. São Paulo: Boitempo editorial, 2003.

XVII Encontro Nacional de Engenharia de Produção, , v. 1, 1997, p. 1-8. 